\title{
Effect of smartphone duration use on scapular muscles strength in normal subjects
}

\author{
Mohamed Soliman MOHAMED ${ }^{1}$, Mohamed Maher ELKEBLAWY'², Doaa Ibrahim AMIN $^{1}$ \\ ${ }^{1}$ Department of Physical Therapy for Basic science, Faculty of Physical Therapy, Cairo University, Egypt \\ ${ }^{2}$ Researcher in National Center of Research, Egypt \\ Corresponding author's Email: msm.physio@gmail.com
}

\section{ABSTRACT}

Background. The use of hand-held devices such as smartphone has been associated with shoulder pain and scapular muscles imbalance as a result of hyperactivity and tightness. Aim. Purpose of this study was to investigate the effect of smartphone duration use on pain of the upper back and scapular muscles strength in normal subjects, Methods. This study was cross sectional observational study; Eighty normal adults 20-30 years age, with right hand dominance were recruited for this study. The subjects must have at least 6 months experience in using smartphone and divided into two groups: Group A used smartphone less than 4 hours daily and group B used smartphone more than 4 hours daily. Subjects was assessed once time. Upper back pain was assessed by Visual Analogue Scale (VAS) scale and strength assessed by break test through pull and push dynamometer. Results. subjects in the two groups showed significant pain accentuation after smartphone usage, depends on the duration. Furthermore, changes in pain severity with smartphone use were different between the two groups ( $\mathrm{P}<0.05)$. For scapular adductor muscles strength, the right dominant side was diminished but not reach to cause significant difference $(P>0.05)$ and the left side have increase in strength with significant difference $(P<0.05)$. Conclusion. Smartphone continuous use for more than 4 hours daily led to increase shoulder or parascapular pain and decrease strength of scapular adductor muscles in right dominant side due to prolonged hyperactivity, then led to weakness and increase the strength of left side due to hyperactivity of left side during holding or static postures and bilateral hand texting.

\section{Original Article}

PII: S225199392000006-10

Rec. 24 May 2020

Rev. 14 June 2020

Pub. 25 July 2020

\section{Keywords}

Upper back pain,

Smartphone,

Scapular muscle strength,

Pull and push dynamometer, Healthy subjects

\section{INTRODUCTION}

The scapula plays an important role in shoulder function and requires both significant mobility and stability. Scapulothoracic motion is a vital component of shoulder function. Adequate motion of the scapula is essential to achieve full range of motion, maintain glenohumeral joint stability, and to elevate the acromion to avoid impingement of the rotator cuff and long head of the biceps tendon beneath the coracoacromial arch during elevation of the arm [1].

Scapular muscles should be balanced or integrated (muscle balance) and worked in synchronized motion, altered scapulothoracic motion in resting position or dynamic motion of scapula described as scapulothoracic dysfunction [2], As a result of muscle imbalance and according to Janda 's classification lower trapezius and rhomboids muscles are one of the most common muscles prone to weakness due to exposure to sustained awkward posture or adaptive postures and restriction to specific activity [3].

Modern people use a smartphone in most areas of their lives, including occupational and leisure activities, which means their duration of smartphone usage is also increasing [4]. Most diseases of the musculoskeletal system are caused by repeated use of the system, which results in damage to the muscular fibers and muscle tone [5].

Therefore, repeated and prolonged use of smartphones will have negative impacts on the human body. Muscular activity of the muscles around the shoulders increased due to smartphone usage [6]. A recent study shows that $79 \%$ of the population between the age 18-44 have their cell phones with them almost all the time, with only 2 hour of their walking day spend without their cell on hand. In addition, looking down at your smart phone too much can lead to upper back pain ranging from chronic, nagging pain to sharp and severe upper back muscles spasm [7]. 
The relationship between smartphone use and musculoskeletal discomfort was related to the duration of ancillary function use. The duration of time spent talking on the phone was a predictor of upper back discomfort [8]. So, the current study was to investigate the effect of smartphone duration use on pain of the upper back and scapular muscles strength (lower trapezius, rhomboids major and rhomboids minor) in normal subjects.

\section{MATERIALS AND METHODS}

The current study was carried out in the outpatient clinic of the faculty of physical therapy on internship students and fresh post graduates in educational staff, Cairo University from November 2018 to May 2020 . To investigate the effect of smartphone duration use on pain of the upper back and scapular muscles strength (lower trapezius, rhomboids major and rhomboids minor) in normal subjects.

\section{Cross sectional observational study}

Eighty normal subjects from both genders with right hand dominance were enrolled in this study. Subjects were divided based on daily duration use of smartphone into two groups: Group A, who used smartphone less than 4 hours daily; Group B who used smartphone more than 4 hours daily. The subjects participated in the current study after approval of Ethical Committee of the faculty of physical therapy, Cairo University with number (P.T.REC/O12/O02137), and all subjects provided written inform consent. All subjects were normal referred with right hand dominance from both genders; subjects were included in this study if they had at least 6 months experience in using touch-screen smartphones and their age ranging from 20 to 30 years. Subjects were excluded from the study if they had any pain or limitation (dysfunction) at neck and shoulder, who have physical difficulties in using smartphones while sitting and standing were recruited? Any congenital abnormalities in either the cervical or the lumbar spine, previous history of severe surgical procedures, any history of upper extremity injury within the past year, visual problems, dizziness and vertigo, any deformity in the upper extremities or spine, neurological or systemic disorders and if they had taken any sedative drug or alcohol within the past 48 hours [9-10].

Initially, subjects were screened against inclusion and exclusion criteria, eligible subjects were informed about the aim of the study and all testing procedures. Then, they were asked to participate in the study, if agreed an informed consent was signed. Basic demographic information as well as questions regarding the average smartphone screen size and the average daily smartphone use was collected from information sheet.

Subjects were assessed once time. During this session, the participant was assessed by analogue baseline pull and push dynamometer from a standardized prone position to assess strength of scapular muscles [11]. Two non-resistive training trials was provide for each muscle group to demonstrate to the subjects the positions and specific muscle group contraction that would have the resistance applied to avoid interference of exercise or training effect. Three measurements of each muscle group were recorded using this technique, to ensure maximal isometric strength and to minimize muscle fatigue.

Each subject was instructed to rate the current level of pain by placing a mark across the horizontal VAS line. The distance in millimeters from the lower limit was measured using a ruler [12]. Calibration of the pull and push dynamometer was performed prior to use according to the manufacturer guidelines. According to Kendall MMT testing parameters (break test) [11], the subject applies a maximal force that is resisted by the examiner. The "breaking force" is the amount of force required to overcome a maximal effort muscle contraction in order to move the shoulder girdle (ST) joint from the initial starting position.

Two major Scapula-humeral muscle groups were test unilaterally (right dominant side then left non dominant side) with the Push-Pull hydraulic type hand held Dynamometer (200N or 20kg), The procedure used to measure scapular muscle strength was adapted from a previous study that reported good between day intra rater reliability for scapular dynamometer strength measurements (ICCs 0.75 to 0.97) [13].

Scapular adduction and depression and also scapular adduction and downward rotation both measured in prone position with head turned to opposite side and therapist stabilize the contra lateral scapula. Three maximum voluntary contractions (MVCs) for the dominant side will be record. The investigator instructed the subject to push into the dynamometer with their maximum effort, holding for 5 second duration. Subjects were instructed to slowly build up their force production to their maximum force before the end of the 5 seconds. The maximum voluntary contractions were recorded by the assessor. An attempt was made to isolate the following muscles. 


\section{Rhomboids muscles}

Subject was positioned prone lying position, shoulder in internal rotation and extension and rest of dorsal surface of hand on ipsilateral gluteal region, therapist resistance applied to medial border of scapula in the direction of scapular abduction and upward rotation that's for scapular adduction and downward rotation [11].

\section{Lower Trapezius}

Subject was positioned prone with arm extended and shoulder held to $135^{\circ}$ of abduction. The dynamometer was placed in the middle line of the scapula, in between the acromion and the medial superior border of the scapula. While the subject lifted his/her arm upward, resistance with the dynamometer was applied in the lateral and superior direction, that's for scapular adduction and depression [13].

\section{Statistical analysis}

Initially, Data were screened for normality assumption, homogeneity of variance, and presence of extreme scores. Kolmogorov-Smirnov test for normality showed that all measured variables are normally distributed. Data were expressed as mean $\pm S D$. Unpaired t-test was used to compare between subjects characteristics of the two groups. MANOVA was performed to compare between groups effects for all measured variables. Statistical package for the social sciences computer program (version 20 for Windows; SPSS Inc., Chicago, Illinois, USA) was used for data analysis. $P$ less than or equal to 0.05 was considered significant. The sample size estimation was based on power analysis. G* power 31 software (university of Dusseldorf, Dusseldorf Germany) was used in the present study with power $80 \%$ and probability 0.05 .

\section{RESULTS}

Data were collected from 80 subjects, that were divided into two equal groups; Group A: forty subjects who use smartphone less than 4 hours daily. Their mean age, weight and height were $22.5 \pm 1.1$ years, $76.6 \pm 12.7 \mathrm{~kg}$, and $176.3 \pm 7.8 \mathrm{~cm}$, respectively. Groupe B: forty subjects who use smartphone more than 4 hours daily. Their mean age, weight and height were $22.6 \pm 1.5$ years, $78.2 \pm 12.8 \mathrm{~kg}$, and $173 \pm 9.7 \mathrm{~cm}$, respectively. There was no significant difference between two groups in their ages, height and weight (p>0.05) as demonstrated in table 1 . The mean

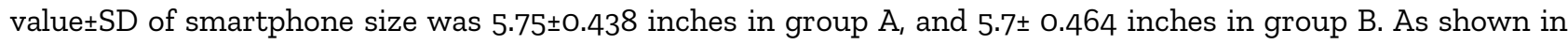
(Table 2). There was no significant difference in the smartphone size between two groups in ( $p=0.622)$.

\section{The effect of different duration of using smartphone on pain of the upper back and scapular muscles strength}

Multivariate Analysis of Variance (MANOVA) was conducted to investigate the effect of smartphone duration use on pain of the upper back and scapular muscles strength (Table 3). There was a significant effect of smartphone duration use on pain of the upper back and scapular muscles strength $(p=0.0001)$.

\section{Comparison of upper back pain between the two groups (Table 4):}

The mean $\pm S D$ of pain in group A was $(0.4 \pm 0.92)$ and group B was and (1 \pm 1.5$)$. There was statistical significant difference in mean values of pain between groups $(\mathrm{P}=0.035)$.

Table 1. Comparison between general characteristics of subjects.

\begin{tabular}{l|c|c|c|c|c}
\hline $\begin{array}{l}\text { General Group } \\
\text { characteristics }\end{array}$ & $\begin{array}{c}\text { Group A } \\
\text { Mean } \pm \text { SD }\end{array}$ & $\begin{array}{c}\text { Group B } \\
\text { Mean } \pm S D\end{array}$ & t-value & P-value & Sig \\
\cline { 1 - 5 } Age $(\mathrm{yrs})$ & $22.5 \pm 1.1$ & $22.6 \pm 1.5$ & -0.421 & 0.675 & NS \\
\hline Weight $(\mathrm{kg})$ & $76.6 \pm 12.7$ & $78.2 \pm 12.8$ & -0.533 & 0.596 & NS \\
\cline { 1 - 3 }$(\mathrm{cm})$ & $176.3 \pm 7.8$ & $173 \pm 9.7$ & 1.66 & 0.101 & NS \\
\hline
\end{tabular}

\section{Table 2.}

\begin{tabular}{lccccc} 
Group & $\begin{array}{c}\text { Group A } \\
\text { Mean } \pm \text { SD }\end{array}$ & $\begin{array}{c}\text { Group B } \\
\text { Mean } \pm \text { SD }\end{array}$ & t-value & p-value & Sig \\
\cline { 1 - 3 } Smartphone size (inches) & $5.75 \pm 0.438$ & $5.7 \pm 0.464$ & 0.495 & 0.622 & NS
\end{tabular}


Table 3. MANOVA

The effect of smartphone duration use on pain of the upper back and scapular muscles strength

$F_{(1.78)}=70.2$ $p=0.0001$

Table 4.

\begin{tabular}{|c|c|c|c|c|c|c|}
\hline Item & Group & $\begin{array}{c}\text { Group A } \\
\text { Mean } \pm S D\end{array}$ & $\begin{array}{c}\text { Group B } \\
\text { Mean } \pm S D\end{array}$ & t-value & p-value & Sig. \\
\hline Upper back pain & & $0.4 \pm 0.92$ & $1 \pm 1.5$ & 4.6 & 0.035 & S \\
\hline
\end{tabular}

P value: Probability value S: Significant

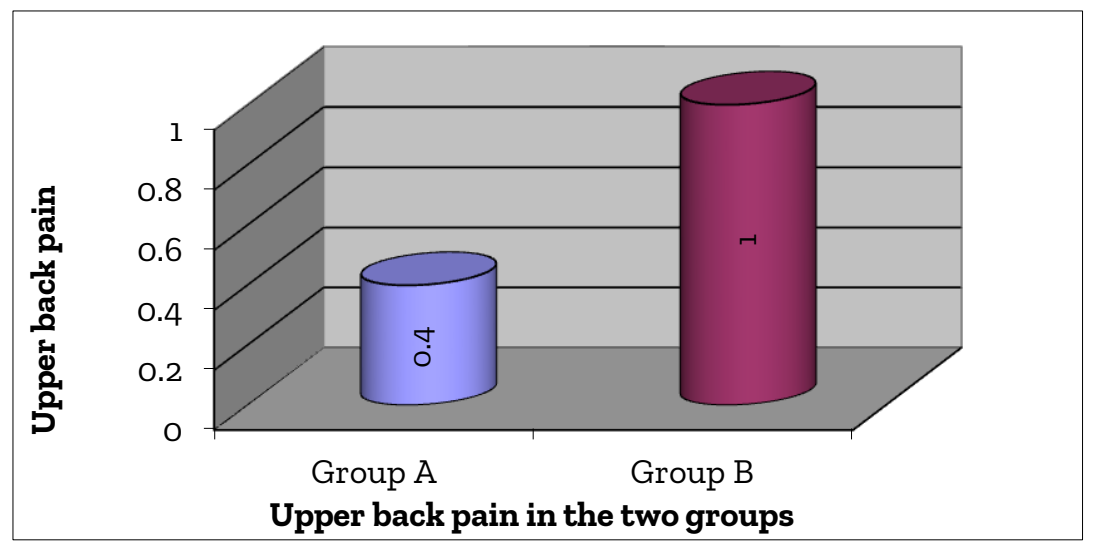

Figure 2. Upper back pain in the two groups

\section{Comparison of scapular muscles strength between the two groups}

Lower trapezius. The mean \pm SD of right lower trapezius in group A was $(7.7 \pm 1.02) \mathrm{kg}$ and group B was and $(7.4 \pm 0.95) \mathrm{kg}$. There was no statistical significant difference in mean values of right lower trapezius between groups $(\mathrm{P}=0.086)$. The mean $\pm \mathrm{SD}$ of left lower trapezius in group A was $(7.15 \pm 1) \mathrm{kg}$ and group $\mathrm{B}$ was and (8.12 \pm 1.2$)$ $\mathrm{kg}$. There was statistical significant difference in mean values of left lower trapezius between groups ( $\mathrm{P}=0.001)$. There were significant differences between the mean values of right and left lower trapezius strength in both groups (Table 5).

Table 5. Comparison of mean value of lower trapezius strength between the two groups.

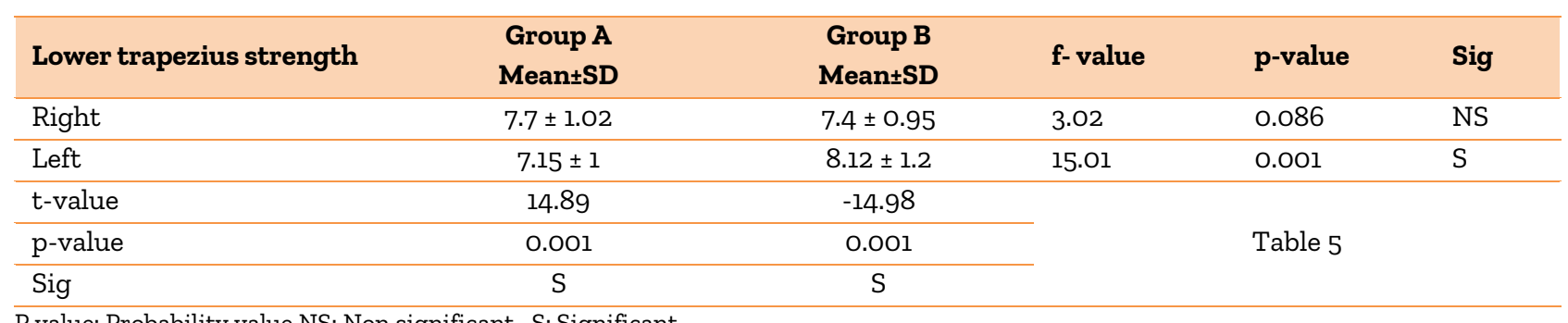

P value: Probability value NS: Non significant S: Significant

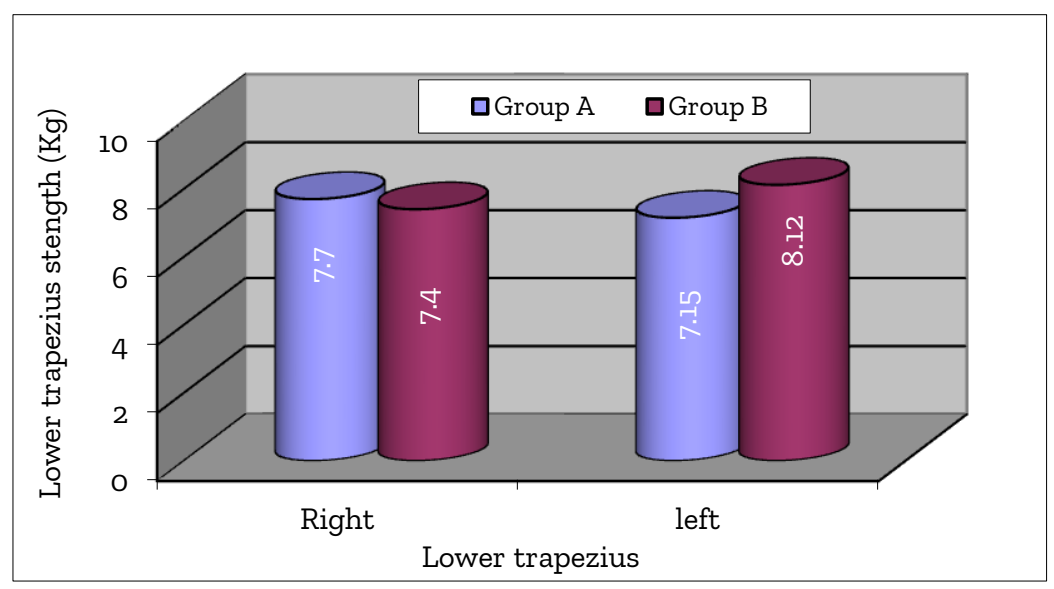

Figure 2. Sterngth of lower trapezius muscles in the both groups 


\section{Rhomboids}

The mean \pm SD of right rhomboids in group A was $(7.5 \pm 1.13) \mathrm{kg}$ and group B was and $(7.3 \pm 0.88) \mathrm{kg}$. There was no statistical significant difference in mean values of right rhomboids between groups $(P=0.495)$. The mean $\pm S D$ of left rhomboids in group A was $(6.9 \pm 1) \mathrm{kg}$ and group B was and $(7.9 \pm 0.84) \mathrm{kg}$. There was statistical significant difference in mean values of left rhomboids between groups $(\mathrm{P}=0.001)$.There were significant differences between the mean values of right and left rhomboids strength in both groups (Table 6).

Table 6. Comparison of mean value of rhomboids between the two groups

\begin{tabular}{|c|c|c|c|c|c|}
\hline Rhomboids strength & $\begin{array}{c}\text { Group A } \\
\text { Mean } \pm S D\end{array}$ & $\begin{array}{c}\text { Group B } \\
\text { Mean } \pm S D\end{array}$ & f-value & p-value & Sig \\
\hline Right & $7.5 \pm 1.13$ & $7.3 \pm 0.88$ & 0.47 & 0.495 & NS \\
\hline Left & $6.9 \pm 1$ & $7.9 \pm 0.84$ & 24.2 & 0.001 & $\mathrm{~S}$ \\
\hline t-value & 14.28 & -12.1 & \multirow{3}{*}{\multicolumn{3}{|c|}{ Table 6}} \\
\hline $\mathrm{p}$-value & 0.001 & 0.001 & & & \\
\hline Sig & S & S & & & \\
\hline
\end{tabular}

P value: Probability value NS: Non significant; S: Significant.

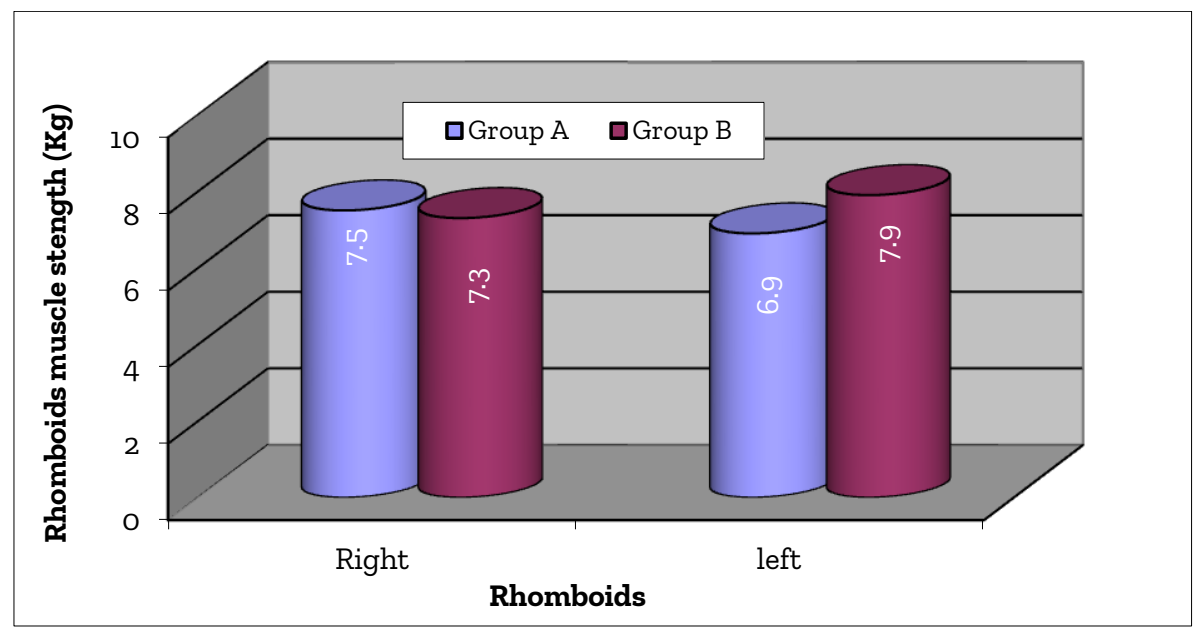

Figure 3. Sterngth of rhomboids muscles in the both groups

\section{DISCUSSION}

Most diseases of the musculoskeletal system are caused by repeated use of the musculoskeletal system, which results in damage to the muscular fibers and muscle tone [5]. The relationship between smartphone use and musculoskeletal discomfort was related to the duration of ancillary function use. The duration of time spent talking on the phone was a predictor of upper back discomfort [8].

The present study was to investigate the effect of smartphone duration use on pain of the upper back and scapular muscles strength (lower trapezius, rhomboids major and rhomboids minor) in normal subjects. In this study, eighty normal subjects were assigned into 2 groups; group A: that use the smartphone for less than 4 hours daily and group B: that use the smartphone for more than 4 hours daily, Both groups assessed through pain assessment by VAS (primary outcome measure) and scapular strength measurement by pull-push dynamometer.

According to the primary outcome measure (pain of the upper back), there was statistical significant difference in mean values of pain between groups $(\mathrm{P}=0.035)$ and the percentage of difference between group $A$ and group B was 150\%, it was meant that group B (subjects use smartphones more than 4 hours) have pain accentuation more than group A (subjects use smartphones less than 4 hours) by $150 \%$, So group A showed mild increase of pain while group B showed high increase of pain in upper back and parascapular area, Eom et al. [14] musculoskeletal symptoms directly proportional with smartphone duration use, supporting the results of the current study.

Smartphone overuse neck and shoulder in an unvarying or static posture due to continuous muscle contraction of these stabilizing muscles which brings to hyperactivity, muscle weakness and easy fatigability that could develop into shoulder and Para scapular pain [15]. 
According to the secondary outcome measure (strength of scapular adductor muscles lower trapezius, rhomboids major and minor which measured by pull-push dynamometer);

1) Comparison between right dominant and left sides in group $A$ and group $B$ reveal that there were significant differences between right and left rhomboids muscles strength values in each group and also between right and left lower trapezius muscle strength values in each group ( $\mathrm{P}=0.001)$. In group $\mathrm{A}$ the daily duration use which less than 4 hours daily does not or slightly affect the strength of right dominant side for both tested muscles (lower trapezius and rhomboids) which was the strongest side [16], keeping the normal statistical significance difference between two sides. But in group B the daily duration use which more than 4 hours daily highly affect the strength of right dominant side and weaken it due to prolonged hyperactivity [6], inverting the strength ratio between right and left sides, in addition to the hyperactivity of left side due to bilateral hand texting or when performing other tasks in the same time of using smartphone, unilateral texting (dominant side) was associated with higher muscle loading and discomfort compared with bilateral texting [9]. This explains the abnormal statistical significance difference between two sides.

2) Comparison between right sides in group $A$ and right sides in group $B$ for both muscles (lower trapezius and rhomboids) reveal that there was no statistical significant difference in mean values of strength between groups, lower trapezius $(\mathrm{P}=0.086)$ and rhomboids $(\mathrm{P}=0.495)$. The right side tested muscles in group $\mathrm{A}$ were affected slightly and the right side tested muscles in group B were affected relatively more than the right side tested muscles in group $A$ but not reach to cause significant difference in mean values of both right lower trapezius strength values and right rhomboids strength values between groups due to the great ability of right dominant side to recover and not easily fatigued. Day et al. [17] reported that the dominant side scapular muscles have higher levels of endurance and probability to recover its self as soon as possible and not easily fatigued, supporting the current study results ( $p>0.05$ ).

3) Comparison between left sides in group $A$ and left sides in group $B$ for both muscles (lower trapezius and rhomboids) reveal that there was a statistical significant difference in mean values of strength for each left sided muscle between groups $(\mathrm{P}=\mathrm{O} .001)$. The results obtained from subjects in the current study indicate similar trends of smartphone usage, with texting and chatting identified as the most popular and time consuming smartphone activity. Forty percent from group A uses bilateral hand texting, More than half the subjects, sixty two percent from group B reported using bilateral hand texting (both thumbs) during the execution of the smartphone-related activities, unilateral texting was associated with higher muscle loading and discomfort compared with bilateral texting [9]. Also, from previous studies when subjects with right hand dominance were many tasks in same time of using smartphones like writing, cooking, driving with calling or texting the static posture was taken by left side to carry and hold the smartphone during calling or texting but if no task performed with calling or texting most of subjects prefer to hold the smartphone by right dominant side during call and use bilateral hand texting. Right-hand holding/typing was not favored, due to increased muscle activities and slower typing speed [18].

Furthermore, the present study are in agreement with that who Cochrane et al. [6] reported as a result of the photographic postural analysis for short-term effect of smartphone usage on the upper-back postures of university students, there was a significant increase $(p=0.000)$ in the amount of shoulder protraction on the left hand side (non-dominant) hands of the students. Increased shoulder protraction results in dysfunction of the scapula during upper limb movement, which may result in the inability of students to utilize the arm optimally [19], this explains the statistical significant difference in mean values of left lower trapezius muscle strength and also left rhomboids muscles strength between groups.

The current study was inconsistent with those reported by Cools [20] that there were no significant differences in lower and middle trapezius strength for the dominant compared to the non-dominant limb. The present study may be limited to; Small sample, insufficient examiner strength or compensatory movements done by subjects during the measurement can cause poor intra-rater reliability with hand held dynamometer and lacked blind assessor.

\section{CONCLUSION}

Within the scope of this study, the following conclusion was warranted: Continuous using of smartphone for more than 4 hours daily increases shoulder and parascapular pain, fatigue, decrease strength of scapular adductor muscles in right dominant side and increase the strength of left side due to the sustained hyperactivity of left side during holding and static postures. 


\section{REFERENCES}

1. Tsuruike M, Ellenbecker TS. Serratus anterior and lower trapezius muscle activities during multi-joint isotonic scapular exercises and isometric contractions. Journal of athletic training. 2015 Feb 1;50(2):199-210. Google Scholar, https://doi.org/10.4085/1062-605049.3 .80

2. Castelein B, Cagnie B, Cools A. Scapular muscle dysfunction associated with subacromial pain syndrome. Journal of Hand Therapy. 2017 Apr 1;30(2):136-46. Google Scholar, https://doi.org/10.1016/j.jht.2017.03.006

3. Frank C, Page P, Lardner R. Assessment and treatment of muscle imbalance: the Janda approach. Human kinetics; 2009. Google $\underline{\text { Scholar }}$

4. Lee M, Hong Y, Lee S, Won J, Yang J, Park S, Chang KT, Hong Y. The effects of smartphone use on upper extremity muscle activity and pain threshold. Journal of physical therapy science. 2015;27(6):1743-5. Google Scholar, https://doi.org/10.1589/jpts.27.1743

5. Um SH, Choi SY, Park DH. An empirical study on relationship between physical symptoms and smartphone usage. Incheon Inha University, Disertation of master's degree. 2013. Google Scholar

6. Cochrane ME, Tshabalala MD, Hlatswayo NC, Modipana RM, Makibelo PP, Mashale EP, Pete LC. The short-term effect of smartphone usage on the upper-back postures of university students. Cogent Engineering. 2019 Jan 1;6(1):1627752. Google Scholar

7. Neupane S, Ali UI, Mathew A. Text neck syndrome-systematic review. Imperial Journal of Interdisciplinary Research. 2017;3(7):141-8. Google Scholar, PDF

8. Yang SY, Chen MD, Huang YC, Lin CY, Chang JH. Association between smartphone use and musculoskeletal discomfort in adolescent students. Journal of community health. 2017 Jun 1;42(3):423-30. Google Scholar

9. Xie Y, Szeto GP, Dai J, Madeleine P. A comparison of muscle activity in using touchscreen smartphone among young people with and without chronic neck-shoulder pain. Ergonomics. 2016 Jan 2;59(1):61-72. Google Scholar, https://doi.org/10.1080/00140139.2015.1056237

10. Park J, Kim K, Kim N, Choi I, Lee S, Tak S, Yim J. A comparison of cervical flexion, pain, and clinical depression in frequency of smartphone use. International Journal of Bio-Science and Bio-Technology. 2015;7(3):183-90. Google Scholar

11. Knepler C, Bohannon RW. Subjectivity of forces associated with manual-muscle test grades of 3+, 4-, and 4. Perceptual and motor skills. 1998 Dec; 87(3_suppl):1123-8.Google Scholar, https://doi.org/10.2466/pms.1998.87.3f.1123

12. Balagué F, Mannion AF, Pellisé F, Cedraschi C. Non-specific low back pain. The lancet. 2012 Feb 4;379(9814):482-91. Google Scholar, https://doi.org/10.1016/S0140-6736(11)60610-7

13. Michener LA, Boardman ND, Pidcoe PE, Frith AM. Scapular muscle tests in subjects with shoulder pain and functional loss: reliability and construct validity. Physical therapy. 2005 Nov 1;85(11):1128-38.Google Scholar, https://doi.org/10.1093/ptj/85.11.1128

14. Eom SH, Choi SY, Park DH. An empirical study on relationship between symptoms of musculoskeletal disorders and amount of smartphone usage. Journal of the Korea Safety Management and Science. 2013;15(2):113-20. Google Scholar, https://doi.org/10.12812/ksms.2013.15.2.113

15. Kim HJ, Kim JS. The relationship between smartphone use and subjective musculoskeletal symptoms and university students. Journal of physical therapy science. 2015;27(3):575-9. Google Scholar, https://doi.org/10.1589/jpts.27.575

16. Senthil P, Radhakrishnan. R. Normative Data and Intra -Rater Reliability of Scapula -Humeral Muscle Strength Using Push -Pull Hydraulic Type Hand Held Dynamometer in Healthy College Students. International Journal of Health Sciences and Research. 2016: 1(7), 7-16.

17. Day JM, Bush H, Nitz AJ, Uhl TL. Arm dominance does not influence measures of scapular muscle strength and endurance in healthy individuals. Physiotherapy Practice and Research. 2015 Jan 1;36(2):87-95. Google Scholar, DOI: 10.3233/PPR-150056

18. Ko PH, Hwang YH, Liang HW. Influence of smartphone use styles on typing performance and biomechanical exposure. Ergonomics. 2016 Jun 2;59(6):821-8. Google Scholar, https://doi.org/10.1080/00140139.2015.1088075

19. Andersen $\mathrm{CH}$, Andersen LL, Zebis MK, Sjøgaard G. Effect of scapular function training on chronic pain in the neck/shoulder region: a randomized controlled trial. Journal of occupational rehabilitation. 2014 Jun 1;24(2):316-24. Google Scholar, PDF

20. Cools AM, Johansson FR, Cambier DC, Velde AV, Palmans T, Witvrouw EE. Descriptive profile of scapulothoracic position, strength and flexibility variables in adolescent elite tennis players. British journal of sports medicine. 2010 Jul 1;44(9):678-84. Google Scholar, http://dx.doi.org/10.1136/bjsm.2009.070128 